\title{
Practicing Management "By Walking Around" and Its Impact on the Organizational Commitment in the Jordanian Hospitals
}

\author{
Dr. Ata E. M. AL Shra'ah \\ Department of Business Administration \\ AlBalqa Applied University, AL-Salt, Jordan \\ Dr. Mohammed Abu Rumman \\ Department of Business Administration \\ AlBalqa Applied University, AL-Salt, Jordan \\ E-mail: mohammad_n_k_s@yahoo.com \\ Dr. Husam M. J. Abu Hamour \\ Department of Business Administration \\ AlBalqa Applied University, AL-Salt, Jordan \\ Dr. Ishaq M. AL Sha"ar \\ Department of Business Administration \\ AlBalqa Applied University, AL-Salt, Jordan
}

Received: Nov. 20, 2012

Accepted: December 11, 2012 Published: January 1, 2013

doi:10.5296/jmr.v5i1.2740

URL: http://dx.doi.org/10.5296/jmr.v5i1.2740

\begin{abstract}
This study aimed at showing the role of practicing management "by walking around" on the organizational commitment in the Jordanian hospitals among doctors and nurses. The sample of the study consisted of (106) male and female doctors, and (440) male and female nurses who work in the public and private hospitals in Jordan. A questionnaire was developed to
\end{abstract}




\section{Macrothink}

measure the variables of the study which consists of (71) items; (35) items which measure practice management" by walking around" and (15) items to measure the organizational commitment. Means, standard deviation and multiple regression tests were used to answer the questions of the study and test its hypothesis. The main results of the study are as follows:

- The degree of the doctors and nurses' practice of management "by walking around" in the Jordanian was medium.

- The level of the organizational commitment of the doctors and nurse was medium.

- There was statically significant impact for practicing management "by walking around" on the organizational commitment of the doctors and nurses at the Jordanian hospitals.

In the light of the study results, the study presented a set of recommendations: Encourage the doctors and nurses to practice management "by walking around", and to cooperate with the managers to make the work successful. In addition to provide the individuals (employees) with training programs that help them to improve their skills in practicing management "by walking around" which enhances making relations based on the mutual respect and trust between the manager and the employees.

Keywords: Management, Organizational, Commitment, Hospitals 


\section{Introduction}

Health services in Jordan witnessed qualitative and quantitative expansion in all the levels and medical sectors in the public and private sectors in the last century. The private sector witnessed after 1990 a steady growth in the number of the private hospitals. In 2002, King Abdullah University Hospital was built and established, while the latest achievement was the opening of Prince Hamza Hospital in Tabarbour in Amman.

The medical work depends on "walking around "between patients and employees to provide medical services, and all the doctors and nurses adopt this technique at their work. Management "by walking around" is considered as one of the modern administrative techniques that based on integrating the managers' leading behavior with their management behavior to achieve successfully the goals of the organization, effectively and efficiently. In light of this technique, the manager remains in the actual field of work, and employs his skills and traits in communication with the employees, directs them, provides them with advice and guidance. Furthermore, this technique helps the manager to know what is happening in the organization, discuss the employees, know their problems and identify the employees' individual capabilities.

The application of management "by walking around" may succeed in the industrial companies, educational and health organizations. Management "by walking around" means that managers leave their offices, and walk among the employees in organisation to define their needs and problems. The management "by walking around" allows all the employees with their different organizational levels to express their views directly to their manager. The main benefits of this technique include development of employees' skills (such as leadership, knowledge, and work experience etc), and development of work procedures and requirements etc.

Management "by walking around" is seen as a strategy of communication between the manager and the employees, relying on the informal contacts by adopting the decentralized management approach and the trust in the employees, which enhances the teamwork. Management by "walking around" keeps space-time continuum between the manager and his employees and thus develops the employees' positive attitudes towards the work.

\section{The Problem of the Study and its questions}

According to the nature of the work at the Jordanian hospitals, and its dependence on work teams, the variety of resources and experiences, and their need to the skills of communication, applying the concept of management "by walking around" may increase their success in achieving their goals, developing the skills of both; the manger and the employees. The applying of management "by walking around" in the Jordanian hospitals may enhance the organizational commitment. Since, there is a shortage in the literature regarding to the effects of applying management "by walking around". Subsequently, the purpose of this study is to know the role of management "by walking around" in enhancing the organizational commitment in the Jordanian hospitals. The elements of the study are seen by answering the following questions: 
- What is the degree of the doctors and nurses' practice of management "by walking around" in the Jordanian hospitals?

- What is the level of the doctors and nurses' organizational commitment in the Jordanian hospitals?

- Is there an impact of management "by walking around" on enhancing the organizational commitment of the doctors and nurses in the Jordanian hospitals?

\section{Hypotheses of the study}

This study tried to test the following hypothesis:

\section{The main hypothesis (HO)}

There is no statically significant impact at $(\alpha=0.05)$ of practicing management "by walking around" on the organizational commitment of the doctors and nurses in the Jordanian hospitals.

\section{The following sub-hypotheses arise from this basic hypothesis}

The first sub-hypothesis (H0): there is no statically significant impact at $(\alpha=0.05)$ of practicing management by "walking around" on the emotional commitment of doctors and nurses in the Jordanian hospitals.

The second sub-hypothesis (H0): there is no statically significant impact at $(\alpha=0.05)$ of practicing management by "walking around" on the continuous commitment of doctors and nurses in the Jordanian hospitals.

The third sub-hypothesis: there is no statically significant impact at $(\alpha=0.05)$ of practicing management by walking around" on the standard commitment of doctors and nurses in the Jordanian hospitals.

\section{The model of the study}

Based on reviewing the previous studies, the researcher designed the model of this study; management "by walking around" is the independent variable, while the organizational commitment is the dependent variable. Figure (1) below shows the model of the study.

\section{Management by "Walking Around"}

The first researchers who discussed management "by walking around" were Peters and Waterman (1982) in their book "Looking for Excellence". They showed that the companies which its managers interact with the employees and the customers were more successful than other companies, whose managers were way from the employees and the customers. Practicing management "by walking around" motivates the managers and the employees to face the problems of the work by the continuous communication between them. Management "by walking around" represents the philosophy of management, which based on getting rid of the traditional tasks of manager as clerical work and managing business away from the office. 
Management "by walking around" means that the managers leave their offices and be with their employees in their sites, and communicate with them. This way allows the managers to identify the problems of work and employees. On the other hand, the managers provide the employees with modern and developed work techniques, which help them to achieve their goals and face their problems. Deming, one of the Quality philosophers, said. "If you wait others to come to you, you will gain few problems; so you have to go to them" (Peters and Austin, 1989).

In the same context of talking about the problems, which the employees face in the organizations, most of these problems are similar in all different organizations. The managers face difficulty in discovering these problems unless the employees or the customers pointed at them or revealed them. Therefore, the technique of management "by walking around" is considered one of the effective techniques used to reveal these problems on the ground, when the managers leave their offices. Management "by walking around" facilitates the process of communication with the employees and the customers (Lorenzen, 1997).

\section{The Organizational Commitment}

Organizational commitment is the process of compatibility and similarity between the individual's goals and the organization's goals (Hall et al., 1970). Sheldon (1971) revealed that organizational commitment is employee's positive evaluation to his organization and his devotion at work to achieve the goals of organization. Organizational commitment is an individual's attitude towards the perceived interest or the benefit because of taking part and continuous contribution in the organization (Hrebiniak and Alutto, 1972). Buchanan (1974) defined organizational commitment as individual's integration within an organization where the employee expresses his desire to serve the organization significantly. Whereas, Porter et al., (1978) believed that the organizational commitment reflects the individual belief in the goals and the values of the organization, and accept these goals and values, and the desire to exert reasonable effort in behalf of the organization and the strong wish to remain in it. Moreover, Rugby (2004) explained that organizational commitment is the extent of the individual's proud of organization.

Mowday et al., (1982) believed that the organizational commitment based on three basic elements: the strong belief of the organization's goals and values, and the extent of accepting it, the readiness to exert efforts in the organization, and the intention to remain a member in the organization. Wiener (1982) considered that the organizational commitment is the total of pressures that motivate the individual to behave in a way to achieve the goals and the interests of the organization. O' Reilly and Chatman (1990) agreed with Wiener that they considered organizational commitment as the psychological connection which the individual feels towards the organization and which reflects the degree of the individual's adoption of the features and the characteristics of the organization. Mathieu and Zajac (1990) assured that organizational commitment is the relation that links the individual with an organization.

Dockel (2003) defined the organizational commitment as a psychological state links the employee with an organization. The outcome of organizational commitment includes: the 
boost of organizational performance, improvement of attendance and loyalty, and shortage in cycling the work, creativity and cooperation of productive work.

\section{The Previous Studies}

Al-Saleh (2011) in his study aimed to reveal the impact of emotional intelligence on enhancing the organizational commitment of the educational leaders of the governmental departments in Tabouk in the Kingdom of Saudi Arabia. The study concluded that there was statically significant impact of the emotional intelligence with its dimensions on the organizational commitment of the administrative leaders of the governmental departments in Tabouk in the Kingdom of Saudi Arabia.

Alaidi (2010) conducted a study which aimed at showing the impact of practicing "management by walking about" on the effectiveness of decision-making process in the Jordanian public universities. The sample of the study consisted of (361) individual. The findings of the study showed that there were statically significant differences of practicing "management by walking around" with its dimensions on the efficiency of decision -making process in the Jordanian public universities.

Beil-Hildebrand (2006) investigated the effects of applying "management by walking around" on healthcare employees in one of German hospitals, assuming that this application enhanced the employees' commitment and support high trust work relations. The findings of the study revealed that there were positive impact of using the style of management "by walking around" by the managers on the employees' confidence and enhancing the group work. The findings of the study also revealed the level of commitment and motivation of employees was high.

Al-Harahsha and Al-Bashabsha (2006) conducted a study to analyze the impact of the employees' needs (achievement, power, loyalty) on the organizational commitment. The findings of the study showed that there was statically significant impact of the employees' needs on their organizational commitment. Moreover, there was statically significant impact of the employees' needs on their emotional commitment, continuous commitment, and their ethics commitment.

Hanona (2005) examined the organizational commitment of the employees in the Palestinian universities in Gaza Strip. The study applied on a random sample consisted of (340) male and female employees. The sample was distributed according to the nature of the work, and the level of education. The main findings of the study indicated that there was a high level of organizational commitment among the employees of the Palestinian universities in Gaza Strip.

Mckinney (2004) in his study aimed at showing the level of the nurses' satisfaction on work in correlation with time, which the managers spent with them during their "walking around" among the nurses. The findings of the study showed that the managers' observations during their "walking around" contributed to the modification of work instructions for completing the tasks effectively. The positive correlation between the time which the managers spent during "walking about "and the availability of a comfortable work environment helps in 
achieving the nurses' demands, and their comfort. The study also showed that there was a relation between the nurses' satisfaction and the time the managers spent with the nurses.

Tribolet (2004) conducted a study to reveal the relation between the intrinsic and extrinsic motivation and the organizational commitment of the employees. The findings showed that Swiss employees' were more intrinsically motivated than extrinsically, the greater their intrinsic motivation and the greater their degree of organizational commitment. Furthermore, those who were highly extrinsically motivated showed lower organizational commitment than others did.

Schneider (2003) examined the relation between the organizational commitment and job satisfaction and job characteristics of the employees of the healthcare institutions in Taiwan. The study focused on three axes: (the organizational commitment, job satisfaction, and types of leadership). The findings of this study indicated that there was a relation between the organizational commitment and the emotional commitment, and there was a strong relation between the types of leadership and the organizational commitment. Te findings also showed that the types of leadership, which were used by the managers, had direct impact on job satisfaction of the employees, and there was a strong relation between the organizational commitment and the type of leadership and its reflections on job satisfaction.

Amsbary and Staples (1991) investigated the improvement of communication by applying "management by wandering about" in improving the communication between the administration and female nurses in the hospitals. The findings of first survey showed that the nurses looked at the "management by walking about" as a time for mangers to monitor, interact and identify the problems. The findings of second survey showed that the administrative rounds are an opportunity for the managers to observe their units, and an opportunity to evaluate their performance.

\section{Methodology of the Study}

The interpretive approach has been used to identify the impact of management "by walking around" on the organizational commitment of the doctors and the nurses in the Jordanian hospitals. Relying on reviewing the theoretical literature related to the "management by walking about", the organizational commitment, the organizational confidence and other related studies. The researchers have adopted the survey through questionnaires to collect data, which used in Alaiedi study (2010). They employed SPSS to analyze data, to reveal results and then to build up the recommendations.

\section{The population of the study}

The population of the study consisted of the Jordanian hospitals in Amman, the capital which are about (40) hospitals; three were government hospitals, and thirty-seven were private hospitals. The number of the doctors and nurses in Jordanian government hospitals was as follows: (964) doctors and (2377) nurses, while the number of the doctors and nurses who work in the private hospitals was (1094) doctors and (2071) nurses (Ministry of Health, 2009). 


\section{The sample of the study}

A stratified sample was selected from the population of the study with a percentage of $(10 \%)$ from the doctors and nurses in the government and private hospitals. The sample consisted of (651) doctor and nurse; (96) doctors and (238) nurses work in the government hospitals, and (110) doctors and (207) nurses work in the private hospitals. A questionnaire was distributed on the sample of study. 593 questionnaires were retrieved: (126) doctors' questionnaires and (467) nurses' questionnaires, while (20) of doctors' questionnaires and (27) of nurses' questionnaires were excluded for their inappropriateness for analysis. Therefore, the sample of study becomes (106) doctors and (440) nurses.

\section{The tool of the study}

To achieve the goals of this study, a questionnaire was developed to measure the independent and dependent variables, by reviewing the theoretical literature related to the management "by walking around", the organizational commitment, and having an access on the tools used in the previous studies as Alaiedi study (2010), Beil-Hildebrand study (2006)regarding the measure of "management by walking around" and the study of Andoras(2006) and Al-Kasasbah's study( 1996) concerning measuring the organizational commitment.

\section{Statistical Treatment of Data}

Statistical Packages for the Social Sciences (SPSS) were used to analyze data descriptively and interpretively. Frequencies and percentages were used to identify the characteristics of the population of the study. Means and the standard deviation were used to analyze the items of the questionnaire and arrange them according to their importance. Multiple regression was used to examine the hypothesis of study, to answer the questions of study, to discuss the results, and then to build up the conclusions.

\section{The validity of the tool of the study}

The initial draft of questionnaire was distributed on ten arbitrators of professors of management in the Jordanian public and private universities to verify the apparent validity of the questionnaire in measuring the independent and dependent variables and to express their views and suggestions regarding; the degree of the items' representation of management "by walking around", and the organizational commitment, and their comprehensiveness. Accordingly, changes were made in the light of the arbitrators' suggestions, views and notes.

\section{The Reliability of survey's dimensions}

The internal consistency of the questionnaire was calculated to verify the reliability of questionnaire. Cronbach Alpha was used to test the internal consistency for each variable within its dimensions. The reliability of all the variables was high, and it is considered good and acceptable percentage in the human studies and researches. Table (1) illustrates the test's results. 


\section{First: The answers for the questions of the study}

The first question: What is the degree of doctors' and nurses' practice of management "by walking round" in the Jordanian hospitals?

To answer this question, the means and the standard deviation of the degree of doctors' and nurses' practice of management "by walking around" in the Jordanian hospitals were calculated. Table (2) illustrates the results.

Table (2) illustrates that the degree of doctors' and nurses' practice of management "by walking around" is medium, with a mean (3.35) and standard deviation (0.468). It is clear that the dimension of discovering the facts comes first with mean of (3.56), followed by the dimension of development and creativity with mean of (3.35), followed by the dimension of improving communication with a mean of (3.32), followed by the dimension of feedback with a mean of (3.30), and in the final rank comes the dimension of motivation with a mean of (3.25). The degree of practicing all of the dimensions was medium.

\section{The Second Question}

What is the level of organizational commitment of the doctors and nurses in the Jordanian hospitals?

To answer this question, the means and the standard deviations of the level of the organizational commitment of doctors and nurse in the Jordanian hospitals were calculated. Table (3) illustrates the results of analysis.

It is clear from table (3) that the level of organizational commitment of doctors and nurses in the Jordanian hospitals is medium with mean of (3.36) and standard deviation (0.495). The dimension of standard commitment comes first with mean of (3.44), followed by the dimension of emotional commitment with mean of (3.33). The dimension of continuous commitment comes in the lowest rank with mean of (3.30). The level of all the dimensions was medium.

\section{Second: Testing the hypothesis of the study:}

\subsection{The main hypothesis}

There is no statically significant impact at $(\alpha \leq 0.05)$ of practicing management by walking around" on the organizational commitment of doctors and nurses in the Jordanian hospitals.

To test this hypothesis, the multiple regression test was used to identify the impact of practicing management "by walking around" with its dimensions (discovering facts, improving communication, motivation, development and creativity, and feedback) on the organizational commitment of doctors and nurses in the Jordanian hospitals. Table (4) illustrates the results of the test.

It is clear from table (4) that value of the calculated (f) is (147.819) with a possible value $(0.000)$ and it is less than $(\alpha=0.05)$, which means that there is statically significant impact of practicing management by walking around on the organizational commitment of doctors and 
nurses in the Jordanian hospitals. It is clear from the table that the independent dimensions (discovering facts, improving communication, motivation, development and creativity, feedback) explains (57.8\%) of the differences in the organizational commitment of doctors and nurses in the Jordanian hospitals. According to these results, the substitute hypothesis is accepted: "There is statically significant impact at $(\alpha \leq 0.05)$ of practicing "management by walking around" on the organizational commitment of doctors and nurses in the Jordanian hospitals."

\subsection{The First Sub-Hypothesis}

There is no statically significant impact at $(\alpha \leq 0.05)$ of practicing management "by walking around" on the emotional commitment of doctors and nurses in the Jordanian hospitals.

To test this hypothesis, the multiple regression test was used to identify the impact of practicing management "by walking around" on the emotional commitment of doctors and nurses in the Jordanian hospitals. Table (5) illustrates the results of the test.

According to the table (5), the value of calculated (f) is (54.921) with a significance value of $(0.000)$. This means that there is statically significant impact of practicing management "by walking around" on the emotional commitment of doctors and nurses in the Jordanian hospitals. It is clear from the table that the independent dimensions (discovering facts, improving communication, motivation, development and creativity, feedback) explains $(33.7 \%)$ of the differences in the emotional commitment of doctors and nurses in the Jordanian hospitals. According to these results, the alternative hypothesis is accepted: "There is statically significant impact at $(\alpha \leq 0.05)$ of practicing management "by walking around" on the emotional commitment of doctors and nurses in the Jordanian hospitals."

\subsection{The second sub-hypothesis}

There is no statically significant impact at $(\alpha \leq 0.05)$ of practicing management by walking around" on the continuous commitment of doctors and nurses in the Jordanian hospitals.

To test this hypothesis, the multiple regression test was used to identify the impact of practicing management "by walking around" on the continuous commitment of doctors and nurses in the Jordanian hospitals, and table (6) illustrates the results of the test.

According to the table (6), the value of calculated (f) is (51.546) with significance level of (0.000). This means that there is statically significant impact of practicing management "by walking around" on the continuous commitment of doctors and nurses in the Jordanian hospitals. It is clear from the table that the independent dimensions (discovering facts, improving communication, motivation, development and creativity, feedback) explains $(32.3 \%)$ of the differences in the emotional commitment of doctors and nurses in the Jordanian hospitals. According to these results, the substitute hypothesis is accepted: "There is statically significant impact at $(\alpha \leq 0.05)$ of practicing management "by walking around" on the continuous commitment of doctors and nurses in the Jordanian hospitals."

\subsection{The third sub-hypothesis}

There is no statically significant impact at $(\alpha \leq 0.05)$ of practicing management by walking around" on the emotional commitment of doctors and nurses in the Jordanian hospitals. 
To test this hypothesis, the multiple regression test was used to identify the impact of practicing management "by walking around" on the standard commitment of doctors and nurses in the Jordanian hospitals, and table (7) illustrates the results of the test

It is clear from table (6) that the value of calculated (f) is (152.482) with a significance value (0.000), which means that there is statically significant impact of practicing management "by walking around" on the standard commitment of doctors and nurses in the Jordanian hospitals. And it is clear from the table that the independent dimensions (discovering facts, improving communication, motivation, development and creativity, feedback) explains (58.5\%) of the differences in the standard commitment of doctors and nurses in the Jordanian hospitals. Based on these results, the substitute hypothesis is accepted: "There is statically significant impact at $(\alpha \leq 0.05)$ of practicing management "by walking around" on the standard commitment of doctors and nurses in the Jordanian hospitals.

\section{Findings of the Study}

The study discussed the role of practicing management "by walking around" in enhancing the organizational commitment in the Jordanian hospitals, the following are the most important results of the study:

- The results revealed that the degree of doctors and nurses' practice of management "by walking around" in the Jordanian hospitals was medium. The independent dimensions were arranged respectively as follows: discovering facts, development and creativity, improving communication, feedback, and motivation. The degree of practicing all of these dimensions was medium.

- The results revealed that the level of organizational commitment of doctors and nurses in the Jordanian hospitals was medium. The dependent dimensions are arranged respectively as follows: the standard commitment, emotional commitment and the continuous commitment. The level of all these dimensions was medium.

- The results also showed that there was statically significant impact at $(\alpha \leq 0.05)$ of practicing management "by walking around" on the organizational commitment of doctors and nurses in the Jordanian hospitals.

- The results explained that there was statically significant impact at $(\alpha \leq 0.05)$ of practicing management "by walking around" on the emotional commitment and standard commitment of doctors and nurses in the Jordanian hospitals.

\section{Recommendations}

To enhance practicing management "by walking around" in the Jordanian hospitals through motivating doctors and nurses to practice management "by walking around" and cooperate with the managers to gain successful achievements. In addition to that, there is need to join training programs to develop their skills in practicing the management "by walking around" which enhances relations based on the mutual respect and trust between the managers and the employees. The enhancement of practicing management "by walking around" can be achieved through: 
- Improve the relation with the employees and organize meetings with the employees and the specialists to solve the problems, achieve the employees' demands, and help the managers to find out the creative employees.

- Identify the suitable training programs to develop the employees, and develop the organizational relation among the employees, discover the employees' capabilities and skills and help the employees to know their weak and strong points in their performance.

- Enhance the organizational commitment in the Jordanian hospitals through :

- Develop clear administrative policies in the department, and provide equal opportunities for promoting the employees in the department.

- Apply the regulations and instructions on all the employees without discrimination, and face the problems.

- Grant the authority to the employees and develop objective standards to evaluate the employees' performance and to have the trust in the sources of the information, which they need at work.

\section{References}

Al-Harahshah, M. (2006). Relationship between leadership styles and the level of organizational commitment of teachers: an empirical study on the schools in the province of Tafila. Journal of Educational psychological, 7(1), 13-42. University of Bahrain.

Al-Kasasbeh, M. (1996). The affecting factors in the organizational trust: a field study on the Jordanian civil service, Unpublished Master's Thesis, University of Jordan, Amman, Jordan.

Andrew, R. J. (2006). The degree of practicing the concepts of trust and empowerment among academic leaders in Jordanian universities, unpublished Ph.D. dissertation, University of Jordan: Amman, Jordan.

Al-Obadi, A. (2010). The impact of practicing management by walking around on the effectiveness of the decision-making process: An Empirical Study on the official Jordanian universities, Unpublished Master Thesis, Mutah University: Karak.

Beil-Hildebrand, M. (2006). The Implications of Management by Walking About: A Case Study of a German Hospital. Leadership in Health Services, 19(4), 1-15. http://dx.doi.org/10.1108/13660750610705544

Dockel, A. (2003). The Effect of Retention Factors on Organizational Commitment: An Investigation of High Technology Employees, Unpublished Dissertation, University of Pretoria.

Hall, D. T., Schneider, B., \& Nygren, H.T. (1970). Personal Factors in Organizational Identification, Administrative Science Quarterly, 15(2), 176-90. http://dx.doi.org/10.2307/2391488 
Hanonah, S. (2005). The level of regulatory commitment of the employees in Palestinian Universities, Unpublished Master Thesis, Islamic University: Gaza.

Hrebiniak, L. G., \& Alutto. (1972). Personal and Role Related Factors in Development of Organizational Commitment, Administrative Science Quarterly, 17, 555-572.

Mathieu, J., \& Zajac, D. (1990). A Review of Meta-Analysis of the Antecedents, Correlates and Consequences of Organizational Commitment. Psychological Bulletin, 108(2), 171-94. http://dx.doi.org/10.1037/0033-2909.108.2.171

Mckinney, T. (2004). The Satisfaction of Nurses in Correlation with The Time Nurse Managers Spend with Them. Unpublished Master Thesis, USA: Texas Tech University.

Mohammed A., Alepeshabashh, S., \& Abdul Majeed (2006). Impact needs Makland to commit career of employees in government agencies in the province of Karak, University of Sharjah. Journal of Science Research and Applied, 3(2), 11-54.

Mohammed A. (2011). The impact of emotional intelligence on the enhancement of organizational commitment: case study on the administrative leaders in government departments in Tabuk in Saudi Arabia, Unpublished Master Thesis, Mutah University: Karak, Jordan.

Mowday, R. T., Porter, L. W., \& Steers, R. M. (1982). Employee-Organizational Linkages: The Psychology of Commitment, Absenteeism, and Turnover. New York: Academic Press.

O'Reilly, A., \& Chatman, C. A. (1990). Building Organizational Commitment: A Multi-Firm Study. Journal of Occupational Psychology, 63, 245-261. http://dx.doi.org/10.1111/j.2044-8325.1990.tb00525.x

Peters, J., \& Waterman, J. (1982). In Search of Excellence: Lessons from America's Best Run Companies. New York: Harper \& Row.

Peters, T., \& Austin, N. (1989). A Passion for Excellence: The Leadership Difference. London: Collins.

Porter, L. Steers, R., \& Mowday, R. (1978). Organizational Commitment, Job Satisfaction and Turnover among Psychiatric Technicians. Journal of Applied Psychology, 59(3), 603-609.

Schein, E. (1992). Organizational culture and leadership. San Francisco: Jossey-Bass.

Schneider, Scott. (2003). Organizational Commitment and Job Satisfaction and Job Characteristics of Manager: Examining the Relationship across Selected Demographic Variables. Dissertation Abstract International, A 64/04, P. 13312.

Serrat, O. (2009). Managing by Walking Around. Knowledge Solution, 37, 1 -3.

Sheldon, M. (1971). Investments and Involvements and Mechanisms Production commitment to the Organization. Administrative Science Quarterly, 16(1), 142-150. 


\section{Macrothink}

Journal of Management Research

ISSN 1941-899X 2013, Vol. 5, No. 1

Sison, M. D. (2006). Exploring the roles of Australian communication practitioners in organizational value setting: Agents of conscience, control, and/or compliance?, School of Applied Communication. Design and Social Context Portfolio. Victoria, Australia: RMIT University Melbourne.

Tribolet, Walter. (2004). The Relationship between Intrinsic and Extrinsic Motivation and Organizational Commitment: As Study in a European Environment. Dissertation Abstract International, A 65/03, P. 807.

Wiener, Y. (1982). Commitment in Organizations: A Normative View. Academy of Management Review, 7(3), 418-428

\section{Appendix}

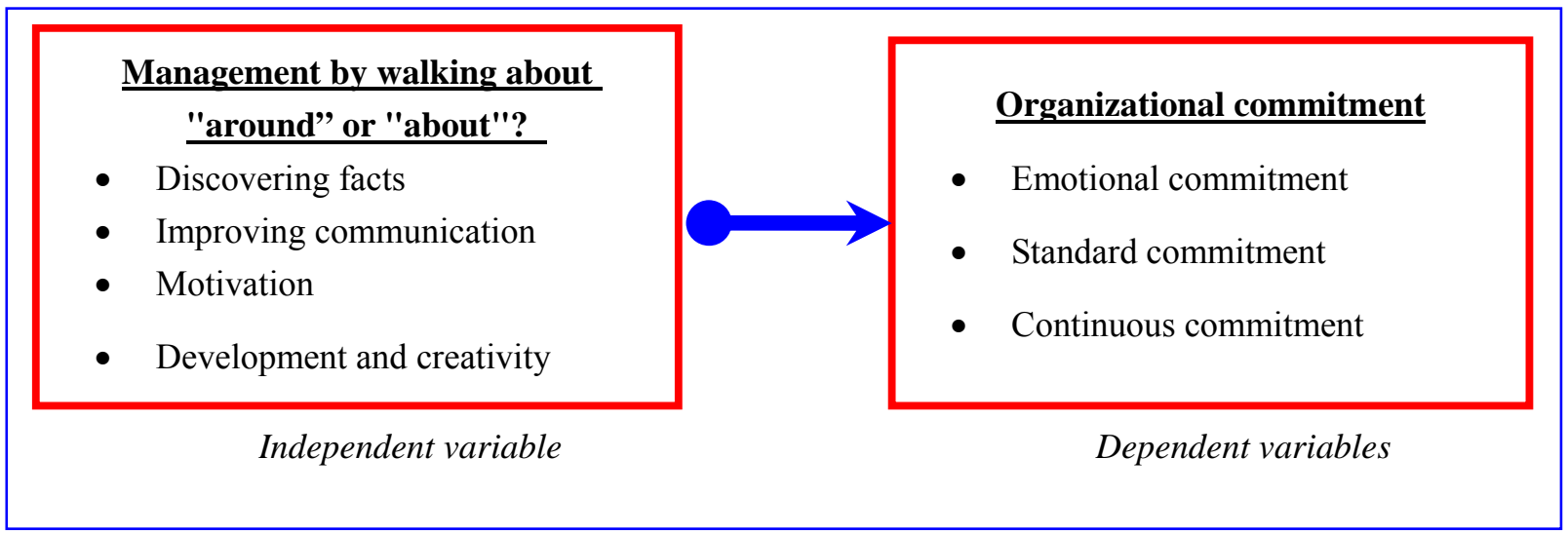

Figure 1. Model of the study

Table 1. Values of Reliability to each variable of the study's variables

\begin{tabular}{|l|l|c|}
\hline Variables of the study & Sub-dimensions & Cronbach's alpha \\
\hline \multirow{4}{*}{ Management "by walking around" } & Discovering facts & 0.84 \\
\cline { 2 - 3 } & Improving communication & 0.83 \\
\cline { 2 - 3 } & Motivation & 0.81 \\
\cline { 2 - 3 } & Development and creativity & 0.87 \\
\cline { 2 - 3 } & Feedback & 0.82 \\
\hline \multirow{4}{*}{ Organizational commitment } & Emotional commitment & 0.87 \\
\cline { 2 - 3 } & Continuous commitment & 0.86 \\
\cline { 2 - 3 } & Standard commitment & 0.89 \\
\hline
\end{tabular}


Table 2. The means and the standard deviation of the doctors and nurses' practice of management by walking about in the Jordanian hospitals arranged descending.

\begin{tabular}{|c|c|c|c|c|c|}
\hline $\begin{array}{c}\text { No. of the } \\
\text { dimension }\end{array}$ & $\begin{array}{c}\text { Dimension of management by } \\
\text { walking around }\end{array}$ & $\begin{array}{l}\text { Standard } \\
\text { deviation }\end{array}$ & Means & Rank & $\begin{array}{l}\text { Degree of } \\
\text { practice }\end{array}$ \\
\hline 1 & Discovering facts & .5560 & 3.56 & 1 & Medium \\
\hline 4 & Development and creativity & .5670 & 3.35 & 2 & Medium \\
\hline 2 & Improving communication & .5330 & 3.32 & 3 & Medium \\
\hline 5 & Feed back & .4240 & 3.30 & 4 & Medium \\
\hline 3 & Motivation & .5760 & 3.25 & 5 & Medium \\
\hline & & .4680 & 3.35 & Total & Medium \\
\hline
\end{tabular}

Table 3. The means and standard deviations of the level of organizational commitment of doctors and nurses in the Jordanian hospitals arranged descending

\begin{tabular}{|c|c|c|c|c|c|}
\hline $\begin{array}{c}\text { No. of } \\
\text { dimension }\end{array}$ & $\begin{array}{c}\text { Dimensions of } \\
\text { commitment }\end{array}$ & $\begin{array}{c}\text { Standard } \\
\text { deviation }\end{array}$ & Means & Rank & $\begin{array}{c}\text { Degree of } \\
\text { commitment }\end{array}$ \\
\hline 3 & Standard commitment & .6760 & 3.44 & 1 & Medium \\
\hline 1 & Emotional commitment & .4860 & 3.33 & 2 & Medium \\
\hline 2 & Continuous commitment & .5090 & 3.30 & 3 & Medium \\
\hline & - & .4950 & 3.36 & total & Medium \\
\hline
\end{tabular}

Table 4. The results of multiple regression test of the impact of practicing management "by walking around" on the organizational commitment of doctors and nurses in the Jordanian hospitals.

\begin{tabular}{|c|c|c|c|c|c|c|}
\hline $\begin{array}{l}\text { Dimensions of management } \\
\text { "by walking around" }\end{array}$ & Beta & $\begin{array}{c}\mathrm{t}- \\
\text { calculated }\end{array}$ & $\begin{array}{c}\text { Significance } \\
\text { level }\end{array}$ & $\boldsymbol{R}^{2}$ & F-calculated & $\begin{array}{c}\text { Significance } \\
\text { level }\end{array}$ \\
\hline Discovering facts & 0.194 & 4.330 & $* 0.000$ & \multirow{5}{*}{0.578} & \multirow{5}{*}{147.819} & \multirow{5}{*}{$* 0.000$} \\
\hline Improving communication & 0.239 & 4.364 & $* 0.000$ & & & \\
\hline Motivation & .1180 & 2.167 & $* 0.031$ & & & \\
\hline Development and creativity & .1760 & 3.324 & $.001 * 0$ & & & \\
\hline Feedback & .1350 & 3.234 & $.001 * 0$ & & & \\
\hline
\end{tabular}

* Significance level at $(\alpha \geq 0.05)$ 
Table 5. The results of Multiple Regression test of the impact of practicing management "by walking around" on the emotional commitment of doctors and nurses in the Jordanian hospitals

\begin{tabular}{|c|c|c|c|c|c|c|}
\hline $\begin{array}{l}\text { Dimensions of management } \\
\text { "by walking around" }\end{array}$ & Beta & $\begin{array}{c}\mathrm{t}- \\
\text { calculated }\end{array}$ & $\begin{array}{c}\text { Significance } \\
\text { level }\end{array}$ & $R^{2}$ & F-calculated & $\begin{array}{c}\text { Significance } \\
\text { level }\end{array}$ \\
\hline Discovering facts & 0.220 & 3.908 & $* 0.000$ & \multirow{5}{*}{0.337} & \multirow{5}{*}{54.921} & \multirow{5}{*}{$* 0.000$} \\
\hline Improving communication & 0.218 & 3.184 & $* 0.002$ & & & \\
\hline Motivation & 0.007 & 0.103 & 0.918 & & & \\
\hline Development and creativity & 0.086 & 1.288 & 0.198 & & & \\
\hline feedback & 0.144 & 2.755 & $* 0.006$ & & & \\
\hline
\end{tabular}

* Significance level at $(\alpha \geq 0.05)$

Table 6. The results of multiple regression test of the impact of practicing management "by walking around" on the continuous commitment of doctors and nurses in the Jordanian hospitals

\begin{tabular}{|c|c|c|c|c|c|c|}
\hline $\begin{array}{l}\text { Dimensions of management } \\
\text { "by walking around" }\end{array}$ & Beta & $\begin{array}{l}\mathrm{t}- \\
\text { calculated }\end{array}$ & $\begin{array}{c}\text { Significance } \\
\text { level }\end{array}$ & R2 & $\begin{array}{l}\text { F- } \\
\text { calculated }\end{array}$ & $\begin{array}{c}\text { Significance } \\
\text { level }\end{array}$ \\
\hline Discovering facts & 0.096 & 1.687 & 0.092 & \multirow{5}{*}{0.323} & \multirow{5}{*}{51.546} & \multirow{5}{*}{$* 0.000$} \\
\hline Improving communication & 0.172 & 2.481 & $* 0.013$ & & & \\
\hline Motivation & 0.049 & 0.718 & 0.473 & & & \\
\hline Development and creativity & 0.110 & 1.630 & 0.104 & & & \\
\hline feedback & 0.221 & 4.185 & $* 0.000$ & & & \\
\hline
\end{tabular}

* Significance level at $(\alpha \geq 0.05)$

Table 7. The results of Multiple Regression test of the impact of practicing management "by walking around" on the standard commitment of doctors and nurses in the Jordanian hospitals

\begin{tabular}{|c|c|c|c|c|c|c|}
\hline $\begin{array}{l}\text { Dimensions of management } \\
\text { "by walking around" }\end{array}$ & Beta & $\begin{array}{l}\mathbf{t}- \\
\text { calculated }\end{array}$ & $\begin{array}{c}\text { Significance } \\
\text { level }\end{array}$ & $\mathbf{R} 2$ & $\begin{array}{l}\text { F- } \\
\text { calculated }\end{array}$ & $\begin{array}{c}\text { Significance } \\
\text { level }\end{array}$ \\
\hline Discovering facts & 0.190 & 4.267 & $* 0.000$ & \multirow{5}{*}{0.585} & \multirow{5}{*}{152.482} & \multirow{5}{*}{$* 0.000$} \\
\hline Improving communication & 0.224 & 4.133 & $* 0.000$ & & & \\
\hline Motivation & 0.188 & 3.484 & $* 0.001$ & & & \\
\hline Development and creativity & 0.213 & 4.045 & $* 0.000$ & & & \\
\hline Feedback & 0.039 & 0.944 & 0.346 & & & \\
\hline
\end{tabular}

* Significance level at $(\alpha \geq 0.05)$ 